\title{
Financial development and oil resource abundance-growth relations: evidence from panel data
}

\begin{abstract}
This study investigates whether financial development dampens the negative impact of oil resource abundance on economic growth. Because of substantial cross-sectional dependence in our data, which contain a core sample of 63 oil-producing countries from 1980 through 2010, we use the common correlated effect mean group (CCEMG) estimator to account for the high degree of heterogeneity and drop the outlier countries. The empirical results reveal that oil resource abundance affects the growth rate in output contingent on the degree of development in financial markets. More developed financial markets can channel the revenues from oil into more productive activities and thus offset the negative effects of oil resource abundance on economic growth. Thus, better financial development can reverse resource curse or enhance resource blessing in oil-rich economies.
\end{abstract}

Keyword: Financial development; Economic growth; Oil resource abundance; Cross-section dependence; Panel data 